\title{
Inhaler Device Preferences in Older Adults with Chronic Lung Disease
}

\author{
Laith Ghazala, $M D^{1}$ \\ Christian Bime, MD MSc ${ }^{1,2}$ \\ Felipe Cortopassi, PT RPFT MBA ${ }^{3}$ \\ Todd Golden, MS $^{1}$ \\ Cristine E. Berry, MD MHS ${ }^{1,2}$ \\ ${ }^{1}$ Department of Medicine and the ${ }^{2}$ Asthma and Airway Disease Research Center \\ University of Arizona College of Medicine \\ Tucson, AZ USA \\ ${ }^{3}$ Pulmonary Department \\ State University of Rio de Janeiro \\ Rio de Janeiro, RJ, Brazil
}

\begin{abstract}
Introduction: Patient preferences are important for medication adherence and patient satisfaction, but little is known about older adult preferences for inhaler devices.

Methods: We developed a 25-item written self-administered questionnaire assessing experience with inhalers, prior inhaler education, and preferences with respect to inhaler device features and inhaler device teaching. We then conducted a cross-sectional survey of patients at least 65 years of age with chronic lung disease who had experience using inhaler devices for at least six months in the ambulatory setting.

Results: Fifty participants completed the questionnaire. The majority of participants (80\%) reported prior experience with a metered dose inhaler (MDI), but only $26 \%$ used an MDI with a spacer. Most patients $(76 \%)$ had received formal instruction regarding proper use of the inhaler, but only $34 \%$ had ever been asked to demonstrate their inhaler technique. Physician recommendation for an inhaler, cost of the inhaler device, and inhaler features related to convenience were important with respect to patient preferences. With regard to inhaler education, participants prefer verbal instruction and/or hands-on demonstration at the time a new inhaler is prescribed in the setting of the prescribing provider's office.

Conclusion: Patient preferences for inhaler devices and inhaler education among older adults indicate physician recommendation, cost, and convenience are important. The impact of patient preferences on inhaler adherence and clinical outcomes remains unknown.
\end{abstract}

\section{Introduction}

Inhalers represent the mainstay of treatment for most patients with chronic lung disease, especially obstructive lung diseases $(1,2)$. There are several different inhaler devices, including pressurized metered-dose inhalers, dry powder inhalers, soft mist inhalers, and nebulizers. Evidence suggests that different inhaler devices are equivalent with respect to drug delivery when the technique for appropriate utilization has been mastered $(3,4)$. However, several factors may influence the ability to use an inhaler 
device properly, such as cognitive function, inspiratory flow rate, or hand strength and dexterity. These issues are particularly relevant to consider when prescribing inhaler devices for older adults (5-7).

The multitude of inhaler devices on the market is growing every day, and while this may allow providers to better tailor therapy to individual patient needs, it also increases the complexity of selecting an inhaler device $(3,5)$. For prescribing providers, it is ever more challenging to consider all the potential factors that may influence both proper use of and adherence to inhaler therapy. Ideally, a provider would assess patient-level factors that impact proper device use and cost of the device to an individual patient, as well as patient preferences. Individual preferences may be shaped by prior experience with inhalers, exposure to advertising, advice from family and friends, lifestyle factors, comorbidities, recommendations from other healthcare providers, and a variety of other factors. Therefore, in selecting an inhaler device for a patient, it is important that providers consider factors beyond those that influence proper inhaler use, as patient preferences may impact adherence to therapy $(3,5)$.

After providers identify an appropriate inhaler device that their patient is capable of using properly (considering physical and/or cognitive limitations) and that is selected based on patient preferences, the next obstacle to achieving maximal inhaler efficacy is ensuring the patient has been properly instructed on the multiple steps required for optimal medication administration from their inhaler device. While the importance of teaching patients about proper inhaler technique has been emphasized in international guidelines for the care of patients with asthma and chronic obstructive pulmonary disease (COPD) $(1,2)$, there is limited information available about patient preferences for device instruction, especially in older adults, including timing, setting, and format of education.

The elderly represent an important population in which inhalers are frequently prescribed but the challenges of inhaler device selection are magnified (6-8). Accordingly, we conducted a single-center cross-sectional study to identify patient preferences for inhaler device features and inhaler device education among older adults in the ambulatory setting. The results of this study have been previously reported in the form of an abstract (9).

\section{Methods}

In order to assess patient preferences regarding inhalers, we developed a 25-item written questionnaire survey (see online supplement). In addition to patient preferences about inhaler device features and inhaler device education, the survey also assessed demographic information, medical history, patient experience with inhaler devices and prior device education, and perceived challenges to proper device use.

Participants were recruited from the ambulatory clinics (pulmonary and internal medicine) and pulmonary function laboratory at Banner University Medical Center in Tucson, Arizona between May 2014 and February 2015. Individuals were included if 
they were at least 65 years of age and had a history of chronic lung disease for which they were prescribed an inhaler device for at least six months. Those who were hospitalized, who did not speak English, or who were unable to read or write were excluded. Surveys were self-administered.

All participants provided written informed consent. This study was approved by the local institutional review board and was conducted according to the ethical principals of the Declaration of Helsinki.

Survey responses were subsequently recorded and tabulated in REDCap (https://projectredcap.org/). Categorical data was described using proportions (N(\%)) and continuous data was described using mean with standard deviation (SD) or median with interquartile ratio (IQR).

\section{Results}

Fifty participants of mean age 74 (range 65-89) years completed the survey, including 22 men and 28 women (Table 1).

Table 1. Study Participant Demographic and Clinical Characteristics

\begin{tabular}{|c|c|}
\hline Participant Characteristic & \\
\hline Age (years) & $74(6)$ \\
\hline Male gender & $21(42 \%)$ \\
\hline $\begin{array}{l}\text { Race/ethnicity } \\
\text { Caucasian } \\
\text { African American } \\
\text { Hispanic } \\
\text { Other / not specified }\end{array}$ & $\begin{array}{r}43(86 \%) \\
1(2 \%) \\
3(6 \%) \\
3(6 \%)\end{array}$ \\
\hline $\begin{array}{l}\text { Living status } \\
\text { Home } \\
\text { Nursing home } \\
\text { Assisted living facility }\end{array}$ & $\begin{array}{r}48(96 \%) \\
1(2 \%) \\
1(2 \%)\end{array}$ \\
\hline $\begin{array}{l}\text { Activities of daily living (ADL) } \\
\text { Independent } \\
\text { Some assistance required } \\
\text { Dependent for ADL }\end{array}$ & $\begin{array}{r}39(78 \%) \\
6(12 \%) \\
5(10 \%)\end{array}$ \\
\hline $\begin{array}{l}\text { Education (highest level completed) } \\
\text { Elementary school } \\
\text { High school } \\
\text { College } \\
\text { Graduate school }\end{array}$ & $\begin{array}{r}3(6 \%) \\
15(30 \%) \\
13(26 \%) \\
19(38 \%)\end{array}$ \\
\hline $\begin{array}{l}\text { Respiratory diagnosis* } \\
\text { COPD } \\
\text { Asthma } \\
\text { Interstitial lung disease }\end{array}$ & $\begin{array}{r}32(65 \%) \\
16(33 \%) \\
5(10 \%)\end{array}$ \\
\hline $\begin{array}{l}\text { Comorbid conditions } \\
\text { Heart disease } \\
\text { Visual impairment } \\
\text { Hearing impairment } \\
\text { Hand arthritis } \\
\text { Stroke } \\
\text { Dementia } \\
\text { None reported }\end{array}$ & $\begin{array}{r}24(48 \%) \\
18(36 \%) \\
16(32 \%) \\
11(22 \%) \\
7(14 \%) \\
1(2 \%) \\
11(22 \%)\end{array}$ \\
\hline
\end{tabular}

$\mathrm{N}=50$; continuous variables are described using mean (standard deviation) and categorical variables are described as $n(\%)$. *Physician diagnosis of respiratory disease; categories are not mutually exclusive and patients may report multiple diagnoses. $\mathrm{COPD}=$ chronic obstructive pulmonary disease. 
The vast majority (96\%) of participants were living at home, and most participants (78\%) reported being independent with respect to activities of daily living. The participants were mostly well-educated, with $26 \%$ having completed college and $38 \%$ with a graduate degree. Comorbid conditions were common, including factors that may influence inhaler use and education, such as visual impairment (37\%), hearing impairment (33\%), and hand arthritis (22\%). Almost all participants reported a physician diagnosis of chronic obstructive pulmonary disease (COPD) or asthma. In addition five patients also reported a history of interstitial lung disease; two of those had mixed history of asthma and ILD.

The majority of participants (80\%) reported prior experience with a metered dose inhaler (MDI), but only $26 \%$ used an MDI with a spacer (Table 2 ).

Table 2. Prior Inhaler Devices Used and Prior Education Regarding Inhalers

\begin{tabular}{|l|r|}
\hline Prior Inhaler Delivery Device Experience & \\
\hline Inhaler Delivery Device* & \\
MDI & $40(80 \%)$ \\
MDI+spacer & $13(26 \%)$ \\
DPI & $17(34 \%)$ \\
Neb & $16(32 \%)$ \\
\hline Prescribing Provider & \\
Pulmonologist & $28(56 \%)$ \\
Primary care physician & $26(52 \%)$ \\
Nurse practitioner & $3(6 \%)$ \\
Allergist & $1(2 \%)$ \\
\hline Prior Inhaler Delivery Device Education & \\
\hline Ever received formal instruction? & \\
Yes & $38(76 \%)$ \\
No & $9(18 \%)$ \\
I don't know & $3(6 \%)$ \\
\hline If formal instruction received (N=38), from whom? & \\
Pulmonologist & $16(42 \%)$ \\
Primary care physician & $16(42 \%)$ \\
Respiratory therapist & $8(21 \%)$ \\
Pharmacist & $3(8 \%)$ \\
Other & $5(13 \%)$ \\
\hline Educational format of device training (N=38) & \\
Verbal instructions & $28(74 \%)$ \\
Written instructions & $7(18 \%)$ \\
Written instructions with illustration & $8(21 \%)$ \\
Hands-on demonstration with sample device & $6(16 \%)$ \\
Hands-on demonstration with patient's own device & $0(0 \%)$ \\
Web-based education including illustrations & $0(0 \%)$ \\
Web-based instruction using video demonstration & $33(66 \%)$ \\
\hline Ever been asked to demonstrate your device technique? & $17(34 \%)$ \\
No & \\
Yes & \\
\hline NE5O & \\
\hline
\end{tabular}

$\mathrm{N}=50$; categorical variables are described as $\mathrm{n}(\%) .{ }^{*}$ Categories are not mutually exclusive as patients may have been prescribed multiple inhaler devices by multiple providers and received formal instruction from multiple providers using multiple educational formats. $\mathrm{MDI}=$ metered dose inhaler, $\mathrm{DPI}=$ dry powder inhaler, $\mathrm{Neb}=$ nebulizer. 
Most patients (76\%) had received formal instruction regarding proper use of the inhaler, but only $34 \%$ had ever been asked to demonstrate their inhaler technique (Table 2).

The majority of participants (66\%) also reported no challenges to using their prescribed inhaler device properly (Table 3 ).

Table 3. Perceived Challenges Influencing Proper Use of Prescribed Inhaler

\begin{tabular}{|l|r|}
\hline Potential Challenge & $\begin{array}{r}\text { Affirmative } \\
\text { Response }\end{array}$ \\
\hline I have not received teaching on how to use it properly. & $3(6 \%)$ \\
\hline $\begin{array}{l}\text { Although I have received some teaching, I cannot } \\
\text { remember how to use it properly. }\end{array}$ & $1(2 \%)$ \\
\hline $\begin{array}{l}\text { I cannot hold my breath during medication } \\
\text { administration. }\end{array}$ & $3(6 \%)$ \\
\hline $\begin{array}{l}\text { I cannot form a tight seal with my mouth around the } \\
\text { device. }\end{array}$ & $2(4 \%)$ \\
\hline $\begin{array}{l}\text { My hand strength and/or dexterity limit my ability to use } \\
\text { the device properly. }\end{array}$ & $0(0 \%)$ \\
\hline $\begin{array}{l}\text { I cannot coordinate my breath and hand action to } \\
\text { administer the medication. }\end{array}$ & $2(4 \%)$ \\
\hline I cannot remember when to take my medication. & $5(10 \%)$ \\
\hline I cannot afford my medication. & $2(4 \%)$ \\
\hline $\begin{array}{l}\text { Visual impairment limits my ability to use the device } \\
\text { properly. }\end{array}$ & $0(0 \%)$ \\
\hline I don't know if my inhaler is expired or not. & $7(14 \%)$ \\
\hline $\begin{array}{l}\text { I use different inhalers at the same time and I get } \\
\text { confused. }\end{array}$ & $1(1 \%)$ \\
\hline None & $33(66 \%)$ \\
\hline Other & $1(2 \%)$ \\
\hline
\end{tabular}

$\mathrm{N}=50$; survey respondents could select more than one answer.

When asked to rate how well they understood the purpose of their inhaled medication ( $1=$ no understanding, $10=$ complete understanding), participants reported good understanding with a median rating of 8 (IQR 6-9). When asked to rate their confidence regarding how well they understood the proper use and handling of their inhaler device (1=no confidence, $10=$ very confident), participants reported a high level of confidence with a median rating of 9 (IQR 8-10).

When asked about the importance of various inhaler features with respect to their own individual preferences, participants provided a rating score ranging from 1 (not important) to 10 (very important) (Table 4). 
Table 4. Patient Preferences Regarding Inhaler Features

\begin{tabular}{|l|r|}
\hline Inhaler Device Feature & $\begin{array}{r}\text { Importance } \\
\text { Rating }\end{array}$ \\
\hline Device is portable & $10(9-10)$ \\
\hline Medication administration time is short & $9(6.5-10)$ \\
\hline Breath hold is not required & $4(1-6)$ \\
\hline Multiple dose device & $9(2-10)$ \\
\hline Tight mouth seal is not required & $3(1-7)$ \\
\hline Regular device cleaning not required & $8(3-9)$ \\
\hline Dosing is once daily & $9(3-10)$ \\
\hline Cost of device & $10(4-10)$ \\
\hline Brand name recognition of device & $3(1-8)$ \\
\hline Physician recommendation of device & $10(10-10)$ \\
\hline
\end{tabular}

$\mathrm{N}=50$; patient ratings are presented as median (IQR) scores and are based on a scale from 1 (not important) to 10 (very important).

Nearly all patients identified physician recommendation of an inhaler device as being very important with a median rating of 10 (IQR 10-10). Other inhaler features that were deemed important by most patients include device portability and short medication administration time. Some factors, such as whether or not an inhaler device required regular cleaning, afforded multiple doses, or was used once daily, received high median scores but demonstrated broader variability in overall response range. Cost of the inhaler was important to many patients as well with a median rating of 10 (IQR 4-10) (Table 4). Although the survey did not ask participants to compare devices, no significant difference was noted in the analysis regarding preferences between those taking nebulizers and those using DPI or MDI.

When asked about their preference for inhaler education format, participants indicated that they preferred hands-on demonstration and/or verbal instructions (Table 5).

Table 5. Patient Preferences Regarding Inhaler Device Education

\begin{tabular}{|l|r|}
\hline Preferred Inhaler Device Education Format (n=47) $^{-47}$ & \\
\hline Verbal instruction & $22(47 \%)$ \\
Written instruction & $0(0 \%)$ \\
Written instruction with illustrations & $9(19 \%)$ \\
Hands-on demonstration with sample device & $17(36 \%)$ \\
Hands-on demonstration with your own device & $16(34 \%)$ \\
Web-based education with written instructions and /or illustrations & $1(2 \%)$ \\
Web-based education with video demonstration & $0(0 \%)$ \\
\hline Preferred Inhaler Device Education Setting (n=47) $^{*}$ & \\
\hline Prescribing doctor's office & $33(70 \%)$ \\
Primary care clinic & $6(13 \%)$ \\
Community event & $0(0 \%)$ \\
Pulmonary function lab or hospital & $12(26 \%)$ \\
In the comfort of my own home & $8(17 \%)$ \\
Other & $6(13 \%)$ \\
\hline Preferred Inhaler Device Education Timing (n=48) & \\
\hline At the time a new medication is prescribed & $34(71 \%)$ \\
At a dedicated follow-up visit immediately after filling prescription & $4(9 \%)$ \\
At a routine follow-up visit after I have filled the prescription & $6(13 \%)$ \\
At every follow-up visit after I have filled the prescription & $1(2 \%)$ \\
Other & $3(6 \%)$ \\
\hline
\end{tabular}

*Some participants did not respond to all questions and thus denominator reflects total $\mathrm{n}$ that responded. Preferences are not mutually exclusive because participants could select multiple options. 
The majority (70\%) would like to receive this teaching at their prescribing doctor's office, and most $(71 \%)$ indicated they would like the education to occur at the time a new inhaler is prescribed (Table 5).

\section{Discussion}

In our cross-sectional survey of patient preferences in older adults with respiratory disease and prior inhaler experience, we determined that physician recommendation for a given inhaler and the cost of the inhaler were very important to patients. Moreover, patient preferences for inhaler features related to convenience were common, including device portability, once daily dosing, short medication administration time, and multipledose devices. The majority of patients also preferred an inhaler device that did not require routine cleaning, such as a nebulizer device. Providers may need to educate patients beyond the purpose of an inhaler by taking time to describe the reasons for selection of a particular inhaler, especially in cases where patient preferences are not aligned with provider objectives in selecting an appropriate inhaler device when there are patient-specific limitations to proper inhaler technique.

This is particularly important for older adults, as we demonstrated in our study that comorbidities that influence proper inhaler use are common among elder patients who have been prescribed inhalers (e.g. hand arthritis, sensory impairment, and stroke). However, in spite of this, we found in our study that spacers remain underutilized, with only a minority of patients who had experience with MDI also reporting prior use with a spacer. Using a spacer in conjunction with a MDI has been recommended for all patients because it minimizes the need for hand-breath coordination and facilitates better drug delivery ${ }^{2}$, but spacers are thought to be especially important for older adults who may experience additional challenges to proper inhaler technique $(7,10)$. Arthritis that limits flexibility and coordination in the absence of weakness could also impact proper device administration.

Overall, study participants reported being quite confident that they understood how to properly use their inhaler, yet only a minority of patients had ever been asked to demonstrate how they use their inhaler. This is in contrast to international guidelines for obstructive lung disease that recommend checking inhaler technique at each visit. ${ }^{1,2}$ Participants also reported very few perceived challenges to proper inhaler use, and several individuals reported no challenges at all, even when they were permitted to provide their own free response in the survey. These findings suggest that patients may underestimate the complexity of inhaler delivery systems and may therefore underappreciate the importance of inhaler education. There are limited data to compare different devices in patients with chronic lung diseases and this was not addressed in our study; however, Komase et al. (11) found that DPI is a preferred device due to its ease of use and association with fewer errors. 
Of note, study participants strongly preferred to receive inhaler education at the time a new inhaler is prescribed in the prescribing provider's office. However, this may be challenging to implement in practice, given the vast number of inhaler devices on the market. Not all clinic staff may be familiar with the features of the different classes of inhaler devices, comparing MDI to DPI to nebulizer, much less feel comfortable teaching about the various features of different DPI devices that are now available. Moreover, placebo devices for patient teaching are not always readily available for each device, which makes it difficult to teach proper use at the time a new device is prescribed. Our study findings indicate participants preferred an educational format of verbal instruction and/or hands-on demonstration, but it may be more feasible for clinic staff to use a web-based video format for initial instruction while patients are still in the office setting and can ask questions as needed and they can then watch the video again at home. This should be followed by another clinic visit to assess proper inhaler technique using the patient's own device shortly after the prescription is filled. Of course, this is particularly important for older adults because they are more likely to demonstrate errors in inhaler technique than younger patients (12).

To date, there is little evidence that taking into account patient preferences regarding inhaler devices results in improved clinical outcomes. However, preferences may influence multiple factors that are important for disease impact, including inhaler device adherence, health-related quality of life, and patient satisfaction with the selected device $(13,14)$. Further research is needed to establish the relationship between patient preferences with inhaler devices and clinical outcomes in patients with obstructive lung disease. The limited evidence to date regarding patient preferences for inhalers suggests that patients find factors related to convenience very important, similar to our findings. For example, Molimard and colleagues (15) showed that dose recording, multiple-dose carrying, and daily dosing were important to patients with COPD and that delivery device features were more critical to patients than the medication compound that was delivered. Ease of use and ability to use the inhaler device during episodes of dyspnea were also found to be important DPI features in a European study of patients with asthma and COPD (16).

The major strengths of this study include that it is patient-centered with an emphasis on patient preferences for inhaler devices and inhaler education. Moreover, we focused on older adults because this special subpopulation often receives inadequate attention, especially in the study of patient preferences, and the physical and cognitive factors that influence proper inhaler use are particularly relevant among elders. We acknowledge that this study is limited in that we did not directly assess proper inhaler use among the participants but instead queried their understanding of proper inhaler use, and therefore we cannot definitively conclude if participants were overly confident or appropriately confident. It is also important to note that our study participants were predominantly Caucasian and also well educated, and therefore the patient preferences we observed may not be representative of all adults with chronic lung disease. Of note, we did not assess use of soft-mist inhalers (SMI) or preferences related to SMI in our survey because they were not widely available in our region at the start of this study. 


\section{Conclusion}

In summary, patient preferences for inhaler devices and inhaler education among older adults indicate physician recommendation, cost, and convenience are important.

Prescribing providers should explain their rationale for inhaler device selection and the importance of inhaler education because patient preferences may not always align with provider priorities or the individual patient-level physical and cognitive factors a provider may consider when selecting an inhaler device.

\section{References}

1. Global Initiative for Obstructive Lung Disease (GOLD). The Global Strategy for Diagnosis, Management and Prevention of COPD (updated 2016). Accessed July 18, 2016 at www.goldcopd.org.

2. Global Initiative for Asthma (GINA). The Global Strategy for Asthma Management and Prevention (updated 2016). Accessed July 19, 2016 at www.ginasthma.org.

3. Yawn BP, Colice GL, Hodder R. Practical aspects of inhaler use in the management of chronic obstructive pulmonary disease in the primary care setting. Int $\mathrm{J}$ Chron Obstruct Pulmon Dis. 2012;7:495-502. [CrossRef] [PubMed]

4. Dolovich MB, Ahrens RC, Hess DR, et al. Device selection and outcomes of aerosol therapy: Evidence-based guidelines: American College of Chest Physicians/American College of Asthma, Allergy, and Immunology. Chest. 2005 Jan;127(1):335-71. [CrossRef] [PubMed]

5. Geller DE. Comparing clinical features of the nebulizer, metered-dose inhaler, and dry powder inhaler. Respir Care. 2005 Oct;50(10):1313-21; discussion 1321-2. [PubMed]

6. Taffet GE, Donohue JF, Altman PR. Considerations for managing chronic obstructive pulmonary disease in the elderly. Clin Interv Aging. 2014;9:23-30. [CrossRef] [PubMed]

7. Barrons R, Pegram A, Borries A. Inhaler device selection: special considerations in elderly patients with chronic obstructive pulmonary disease. Am J Health Syst Pharm. 2011 Jul 1;68(13):1221-32. [CrossRef] [PubMed]

8. Jarvis S, Ind PW, Shiner RJ. Inhaled therapy in elderly COPD patients; time for reevaluation? Age Ageing. 2007 Mar;36(2):213-8. [CrossRef] [PubMed]

9. Ghazala L, Bime C, Cortopassi F, Baalachandran R, Oren E, Berry CE. Inhaler device preferences in older adults with chronic lung disease. Am J Resp Crit Care Med. 2015;191(A5797) [Abstract].

10. Lavorini F, Mannini C, Chellini E, Fontana GA. Optimising Inhaled Pharmacotherapy for Elderly Patients with Chronic Obstructive Pulmonary Disease: The Importance of Delivery Devices. Drugs Aging. 2016 Jul;33(7):461-73. [CrossRef] [PubMed]

11. Komase Y, Asako A, Kobayashi A, Sharma R. Ease-of-use preference for the ELLIPTA $®$ dry powder inhaler over a commonly used single-dose capsule dry powder inhaler by inhalation device-naïve Japanese volunteers aged 40 years or 
older. Int J Chron Obstruct Pulmon Dis. 2014 Dec 11;9:1365-75. [CrossRef] [PubMed]

12. Chorao P, Pereira AM, Fonseca JA. Inhaler devices in asthma and COPD--an assessment of inhaler technique and patient preferences. Respir Med. 2014 Jul;108(7):968-75. [CrossRef] [PubMed]

13. Anderson P. Patient preference for and satisfaction with inhaler devices. Eur Respir Rev. 2005;14(96):109-116. [CrossRef]

14. Shikiar R, Rentz AM. Satisfaction with medication: an overview of conceptual, methodologic, and regulatory issues. Value Health. 2004 Mar-Apr;7(2):204-15. [CrossRef] [PubMed]

15. Molimard M, Colthorpe P. Inhaler devices for chronic obstructive pulmonary disease: insights from patients and healthcare practitioners. J Aerosol Med Pulm Drug Deliv. 2015 Jun;28(3):219-28. [CrossRefl [PubMed]

16. Hawken NA, Amri I, Elmoctar Neine M, Aballea S, Torvinen S, Plich A. Preferences for Dry Powder Inhaler Attributes Among Patients With Asthma and Chronic Obstructive Pulmonary Disease From Five European Countries. Value Health. 2015 Nov;18(7):A364. [CrossRef] [PubMed]

\section{Quick Look}

Current Knowledge:

Inhalers are the mainstay of therapy for obstructive lung disease, but selection of a particular inhaler for an individual can be challenging, particularly in the elderly because of factors related to aging that may influence proper inhaler technique. Providers should also consider patient preferences, but little is known about preferences for inhaler devices among older adults.

What this paper contributes to our knowledge:

Patient preferences for inhaler devices and inhaler education among older adults indicate physician recommendation, cost, and convenience are important. Providers should consider individual patient factors that influence proper inhaler use along with patient preferences when selecting an inhaler. 